\title{
HEREDITARY FORMS OF RICKETS AND OSTEOMALACIA
}

\author{
C. E. Dent, London, England \\ Medical Unit, University College Hospital, London \\ and \\ H. HARris, London, ENGLAND \\ Department of Biochemistry, London Hospital Medical College, London
}

It is becoming clear that the forms of rickets and osteomalacia now met with in this country are almost invariably due to primary metabolic abnormalities rather than to environmental factors. This does not imply an absolute increase in this metabolic form of disease, but only its uncovering by the virtual disappearance of primary nutritional deficiency of vitamin D.

One may perhaps think of classical rickets as it was seen fifty years ago as being largely due to environmental causes, or nurture, and rickets as we see it today as due largely to genetical causes, or nature. The former has been effectively eliminated by an alteration in the diet; the latter seems to develop independently of the living conditions in which the individual is brought up and appears to depend on some inborn biochemical peculiarity in the make-up of the individual.

At the present time, in this and in most other civilised countries, nature has become the more conspicuous factor and therefore apparently the more important since many of the problems of nurture have been largely solved. This demands a considerable reorientation of our approach to our patients' diseases. It is the reason why increasing attention is now being paid to medical genetics and why there is increasing acceptance of the fact that some individuals are constitutionally different from others and develop differently and have different requirements for health even in the same environment.

Nevertheless a sharp distinction between these two factors so far as concerns their contributions to disease processes has never been and can never be complete. In the early days of the study of the pathogenesis of classical rickets hereditary factors had often been suspected (Siegert 1903, Pfaundler 1911, Ziesch 1925) and twin studies, notably by Lehmann (1936), confirmed that such factors were of significance. It is likely that different children require somewhat different amounts of vitamin D to maintain optimal growth and that such variations are, no doubt, at least in part due to differences in their genetical constitutions. When there is an adequate diet such differences in vitamin requirement will be unimportant because the vitamin will be present in excess of requirement for practically all children. However, when the vitamin content of the diet is at a low or borderline level, rickets is likely to become a relatively common disorder and the genetical differences between individuals will become more significant in deciding why one child and not another develops the disease. Thus, while the frequency of classical rickets in a population or stratum of a population may depend largely on the environmental conditions, it could be mainly genetical factors which decide which particular children within the population are going to get the disease. In the past, however, looking at the disease as a whole, these genetical factors never appeared very conspicuous. In the last thirty years, however, vitamin D intake is so much higher than it used to be that the only cases which still get a disease similar to classical rickets are ones in which heredity appears all important.

It is interesting here to note the parallel studies recently done on another action of vitamin $\mathrm{D}$, namely the toxic action. It now appears that some people are far more sensitive than others to vitamin D toxicity, being severely affected by ordinary small anti-rachitic 
doses. This serious disease has only been uncovered recently by the very factor (increased vitamin D intake) which has caused classical rickets to disappear. The sensitivity to vitamin D may occur in infants for an unknown reason (Thatcher 1936; Bonham Carter, Dent, Fowler and Harper 1955), and is the cause of some cases, at least, of the syndrome described by Lightwood (1952) as "idiopathic hypercalcaemia of infancy with failure to thrive." The sensitivity almost certainly occurs also in some adult cases of sarcoidosis (Anderson, Dent, Harper and Philpot 1954; Henneman, Carroll and Dempsey 1954). So far, hereditary factors have not yet been implicated here.

In this paper we are considering some of the forms of rickets and osteomalacia which still occur in spite of this high average intake of vitamin $D$ in our population. Most of these cases have been described under the name of " vitamin D resistant rickets " in the past for the excellent reason that they are very similar indeed to classical rickets, except that the curative dose of vitamin $\mathrm{D}$ is many thousand times greater than is the dose which is anti-rachitic for the vast majority of people.

In an earlier paper to this Journal (Dent 1952) these forms of rickets were described and classified in six main groups according to the degree of abnormality of renal tubule function which was present. This was, and still is, a convenient classification for clinical purposes because it draws attention to a disorder of function which can be readily detected and measured, which is possibly responsible for the bone disease, and which has to be corrected, partly at least, by therapy. The same basis of classification has been independently used by Fanconi (1951) and by Jackson and Linder (1953). In our earlier paper various objections were made to the use of the term " vitamin D resistant rickets," although it was conceded that the classification on the basis of tubule function was also inadequate since it gave no account of other metabolic abnormalities, many of which were similar to those occurring in vitamin D deficiency and which were located elsewhere than in the renal tubule. These and other objections to both forms of classification still hold. The most valid objection to the term "vitamin D resistant rickets" is that it can be equally well used to describe the similar vitamin D resistance occurring in other diseases such as steatorrhoea and renalglomerular failure. This objection we now think has become stronger, for recent work in our department suggests that the mechanism of the vitamin resistance may be similar in all these cases. On the other hand we must now withdraw one of our earlier objections, namely that " vitamin D resistance" could not explain the frequent association of the bone disease with other congenital tubule defects " which have nothing to do with vitamin D " (Dent 1952). We are now beginning to believe that some of these tubule defects, like the phosphate defect, have a great deal to do with vitamin $\mathrm{D}$ action because they are sometimes reversed with the massive vitamin $\mathrm{D}$ therapy used to cure the bone disease.

We will also discuss here our present attempts to distinguish the various clinical types of rickets and osteomalacia of metabolic origin and our preliminary views as to the importance of heredity in their pathogenesis. These studies are beginning to show that there are very many more distinct forms of these diseases than we had previously suspected, and that the problem of classification and nomenclature gets more and more difficult. We propose, therefore, to describe the diseases as such, under rather ponderous names, without committing ourselves to a means of classification. In most of the diseases described our family studies have shown the importance of hereditary factors. However, we include for the sake of completeness some other clinically similar variants of these diseases in which we have so far been unable to prove the influence of heredity. These latter diseases are very rare and we may well uncover hereditary factors when we have been able to study more cases. Cases in which the bone disease appears to be the result of steatorrhoea of any kind or of primary renal-glomerular failure will not be included since the bone disease (and therefore the orthopaedic problem) in such cases constitutes only a minor part of the clinical syndrome and since the influence of heredity in such cases is not yet sufficiently obvious to be of clinical or theoretical value.

VOL. $38 \mathrm{~B}$, NO. 1, FEBRUARY 1956 
Likewise we will make no mention of the forms of rickets and osteomalacia due apparently to renal-tubular acidosis with nephrocalcinosis (Types V and VI of Dent 1952), since these likewise are apparently not hereditary. However, we must mention here in passing the fascinating hereditary form of nephrocalcinosis described by Schreiner, Smith and Kyle (1953). This is probably a completely new syndrome and is not primarily a bone disease. Unfortunately we have no experience of this condition.

We rather fear that a review of this kind of a group of rare medical and orthopaedic conditions will be of only limited interest. We have been encouraged to complete this work by the classic study of Fairbank (1951). His very detailed Atlas of General Affections of the Skeleton, written mainly from a surgical point of view, has proved of extraordinary value to workers in other branches of medicine. We, who are medically and biochemically biased, are now attempting in our small way to continue in the tradition set by this great man using the excuse that this important occasion gives us, and hoping that it too will be of value outside our own very limited field of activity.

\section{DESCRIPTIONS OF THE VARIOUS FORMS OF RICKETS AND OSTEOMALACIA IN WHICH HEREDITARY FACTORS ARE PROVED OR STRONGLY SUSPECTED}

In the following descriptions of the various syndromes we have included data mainly obtained from our own patients but sometimes also from patients kindly referred to us by others but remaining under their care. Unless otherwise stated, however, we have been responsible ourselves for the genetic survey. It may be possible later to publish data in more detail on the individual syndromes concerned. We can only hope here to prepare the way by briefly describing the syndromes and by giving representative genetical data. It will be noted that the syndromes divide themselves into two main groups, the first being patients without renal failure in the ordinary sense of the word but all having nevertheless a renal-tubule defect of phosphate reabsorption. These correspond to the Types I-III of Dent (1952). This defect, as well as some of the other associated biochemical and clinical defects, many of which may also mimic vitamin D deficiency, can be corrected partly at least by treatment with large doses of vitamin D. In the second group (Type IV of Dent 1952) the same defect of renal tubule reabsorption of phosphate with or without other findings reminiscent of vitamin $\mathrm{D}$ deficiency is also present. There is usually a marked renal glycosuria and aminoaciduria. However, these patients have other defects also of renal function, such as proteinuria, inability to secrete a dilute or concentrated urine, a variable, usually slight, degree of nitrogen retention, and so on.

Most of these syndromes have been described by others under various names in the literature, the first group mainly as " vitamin D resistant rickets" and the second as " renal rickets" or "Fanconi syndrome." One of the hereditary diseases we are mentioning here (hypophosphatasia) is not strictly speaking a true rickets according to our usual histological and biochemical definitions. It is included here, however, because the clinical appearances, and to some extent the radiological ones, can cause some confusion with rickets.

\section{FLORID RICKETS PRESENTING IN INFANCY WHICH CLOSELY MIMICS DIETARY DEFICIENCY OF VITAMIN D BUT WHICH REQUIRES ENORMOUS DOSES TO PRODUCE HEALING}

This is the most common form of rickets nowadays in this country and comprises most of the cases of renal-tubular rickets described, as of Type I (Dent 1952),* or by others as refractory or vitamin $\mathrm{D}$ resistant rickets. We have not much data from early life but the little we have suggests that these patients are quite normal clinically and radiologically at birth, and grow and develop normally for the first year of their lives. After this, however, usually

* It is greatly regretted that our theory of renal-tubular defect in this syndrome and of the mechanism of the curative action of vitamin $D$ was put forward in our original publication without knowing and therefore acknowledging that the identical point of view had been previously expressed by Robertson, Harris and McCune (1942). 
before the second year, the child is noticed to be slow in attaining its milestones, and may then show unambiguous rachitic deformities. This is not very conspicuous at first, however, and many are not brought to see the doctor until three or four years of age, by which time dwarfism, lateness in walking, abnormalities of gait and bow legs may have become quite obvious, especially to somebody who sees them for the first time. By then the radiographs will show a florid rickets. Biochemical investigations show a normal plasma calcium, low inorganic phosphate, raised phosphatase and normal bicarbonate. The usual renal function studies give normal results and in particular the urine contains no excessive quantities of aminoacids. As likely as not the patient will have received ample doses of vitamin D from early childhood (1,000-2,000 units a day) and probably will have received larger doses (10,000-20,000 units a day) from other doctors before being referred to us. We suspect that a slight response at first on the somewhat higher range of dosage may sometimes be observed but that this is at best only very temporary. Such a patient has no other biochemical abnormalities that are easy to determine. More detailed investigations, however, also show faulty calcium absorption from the gut and low urinary calcium excretion.

This condition, once developed and left to itself, is constant and incurable. On account of the normal general health of the patients, however, they survive to adult life, when untreated, with varying degrees of deformity, which has usually necessitated osteotomy (Fig. 1). By about fifteen years of age they will be greatly dwarfed (Pedersen and McCarroll 1951), with limbs very small in comparison to the length of the trunk, which is almost normal. They are likely to get aches and pains in their bones during childhood, and to be rather easily tired. When growth has ceased, however, the subjective clinical signs become less conspicuous. Biochemically they maintain the same findings described above, except that the alkaline phosphatase level may return to normal. From the age of about twenty to forty the patient may be symptom-free. Some time after this, however, the pains and radiological signs of osteomalacia are likely to appear and this may be severe enough to cause complete crippling.

It is important perhaps to point out a few differences that there are between this condition and classical rickets due to lack of vitamin D. The main difference, apart, of course, from the dietary history and natural course of the disease, is that in this form of rickets tetany never occurs. The plasma calcium level may be slightly low, somewhere between $9 \cdot 0-10 \cdot 0$, but never falls to tetany levels (less than 7.5) as it so frequently does on and off for some obscure reason in a case of classical rickets of long enough duration. Another difference concerns the muscular weakness and hypotonia, which is so typical of classical rickets and is not very conspicuous in this form of refractory rickets. Indeed, some of these patients, even when untreated, are exceedingly muscular and vigorous, especially when they reach adolescence. Another difference is that cases of classical rickets may have a mild aminoaciduria (Jonxis 1955), unlike the majority of cases of this syndrome.

The treatment of this condition requires the administration of very large doses of vitamin $\mathrm{D}$, something of the order of 5-10 milligrams a day of oral calciferol ( 1 milligram $=40,000$ units) being required to cure the radiological signs and to maintain them cured.

\section{Fig. 1}

Photograph of an adult patient of fifty-four with the severe form of rickets and osteomalacia. Most of his deformities occurred in childhood and were several times corrected temporarily by osteotomy. He was symptom-free from the age of twenty. Recently backache and other pains returned and he thought the deformities were worsening. Until this picture was taken he had had no medical treatment. He is the patient $I 1$ in family tree $R 1$ of Figure 4.

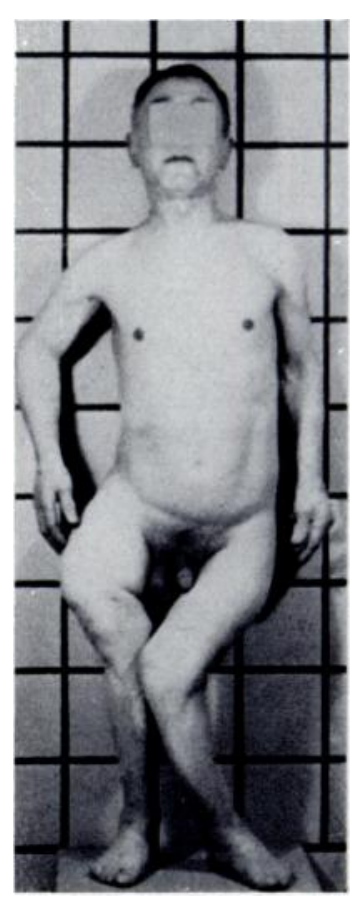

FIG. 1

VOL. 38 B, NO. 1, FEBRUARY 1956 
Under this treatment the metabolic disorders may be entirely corrected (Fig. 2) and much more satisfactory growth and avoidance of deformities obtained, although even then patients tend to end up somewhat dwarfed (Fig. 3). There is great danger of vitamin D intoxication because the toxic dose appears to be only a little more than the dose required to cure the rickets. This is a curious situation, since most normal patients can only be intoxicated by

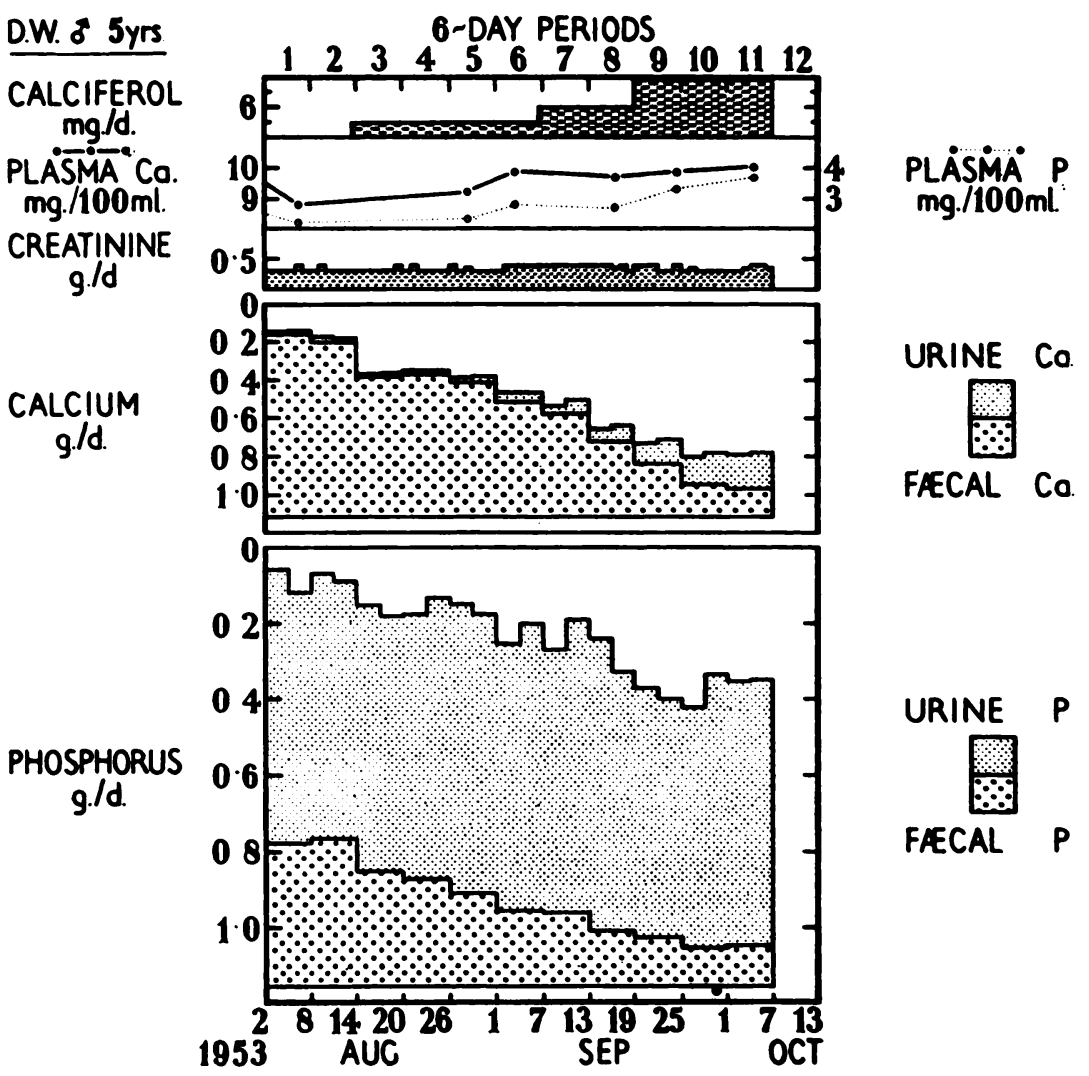

Fig. 2

Metabolic data in a boy of five years with the severe and commonest form of hereditary rickets. The results of giving calciferol are shown. The intake of calcium and phosphorus is measured downward from the zero line: the output of faecal and urinary calcium is measured upwards, hence the clear space below the zero line represents the positive balance or retention of calcium or phosphorus. Before treatment he has a high faecal calcium, low urine calcium and is in smaller positive balance than he should be for his age. These changes are identical with those found in classical rickets. On giving very large doses of calciferol faecal calcium falls considerably. There is a slight rise in urine calcium and he goes into strongly positive calcium balance. Phosphorus balance changes are parallel, but are only half as big as the calcium. This is because calcium phosphate is being laid down as bone in the usual $\mathrm{Ca}: \mathrm{P}$ ratio of approximately $2: 1$ respectively. Plasma levels also become nearly normal during the period of treatment.

These changes are also identical with those occurring after treatment of classical rickets.

similar large doses of vitamin $\mathrm{D}$, while their anti-rachitic requirement of calciferol is very small indeed. The "resistance" to vitamin $\mathrm{D}$ in this disease concerns, therefore, its antirachitic action not its toxic action. This is one of the reasons why we do not like the term "raised resistance to vitamin D" (RRD) introduced by McCance (1947) to describe this and related syndromes.

The treatment of an adult case who presents with symptoms is exactly the same as for the infant, the dose of vitamin D being about the same, and also its hazards. It is easier to define the biochemical criteria for the treatment of a fully grown adult. Our working rule is that we should try and raise the plasma phosphorus to more than 2.5 milligrams/100 millilitres 
with a dose of calciferol which does not raise the plasma calcium to more than 11.5 milligrams: 100 millilitres, nor raise the urine calcium output to more than 400 milligrams/24 hours. When toxicity is developed we prefer to stop treatment altogether until this has been fully recovered from and then to start again with the calciferol.

This treatment of children and adults is only moderately satisfactory and we are further investigating ways of improving it in order to obtain a more normal clinical response with less dangers of toxicity. We hope to publish some improvements in treatment not yet fully confirmed in a further paper. We still cannot make up our minds what to do about a symptom-free patient in the middle age group. It will require very painstaking studies to determine their true status and how far energetic treatment then may avoid later troubles. Usually we do not treat them unless suspicious symptoms appear.

The condition is frequently found in more than one member of the same family, often in different generations. Probably two out of every three affected individuals are derived from parents one of whom is similarly affected. In the remainder of cases both parents appear to be quite normal. A proportion of the children of affected patients also tends to have the same condition. Typical pedigrees are shown in Figure 4.

This kind of familial configuration is consistent with the hypothesis that the disorder is due to a rare abnormal "dominant" gene and the affected individuals are heterozygous for this. Probably the gene is incompletely manifesting: that is to say a proportion of those carrying it does not for some reason show the condition. This could explain why some cases are derived from parents both of whom are apparently quite normal, and why on our present rather small figures it appears that rather less than one in two of the offspring of affected patients are also affected. More convincing proof of such incomplete manifestation would be provided by families in which the condition

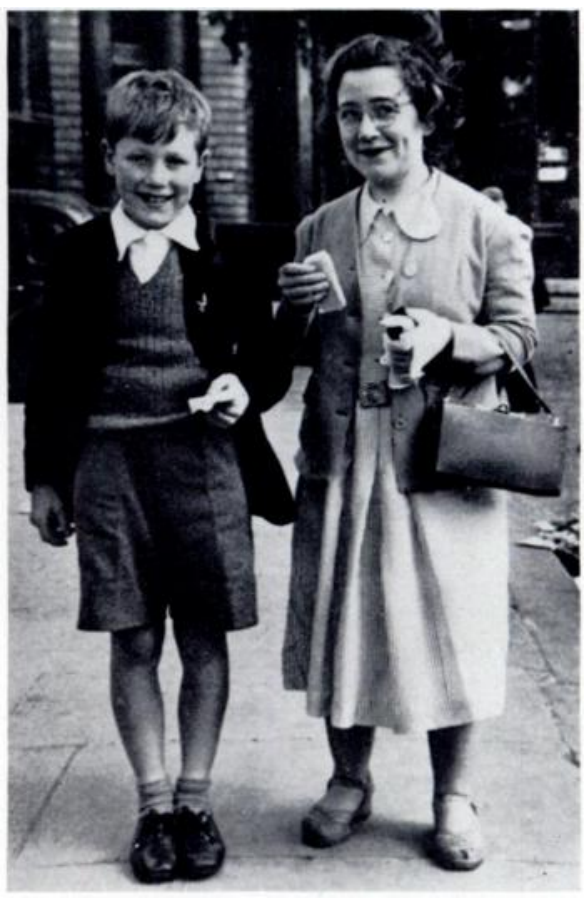

FIG. 3

A girl of twenty-four with the severest and commonest form of hereditary rickets but who otherwise enjoys perfect health. She is the daughter of the patient shown in Figure 1, and is Case II 1 , in family tree R 1 of Figure 4 . She was well treated with fairly large doses of vitamin $\mathrm{D}$ in the early days of this treatment (she was case J. L. of MacKay \& May 1945) and has avoided most of the deformities that her father has had and has required no osteotomy. However, it will be seen that her limbs are relatively short in proportion to her trunk and her stature is small, being about the same as that of her younger normal brother

(II 3) of ten years, seen by her side.

appeared to skip a generation, but so far we have not encountered such a situation ourselves, nor in the literature.

Another possible explanation of the occurrence of apparently sporadic cases, or of families in which a series of affected individuals in more than one generation appears to have originated from a pair of healthy parents (e.g., Family R.8) is the occurrence of fresh mutations. While it is likely that such fresh mutations do occur, and presumably balance the loss of the gene from the population due to the somewhat diminished effective fertility of patients with the disease, it is rather difficult to decide at the moment what proportion of cases do in fact arise in this way.

Considerably more data will be required before the full details of the genetics, the rate of manifestation, and the proportion of cases due to fresh mutation can be established.

VOL. $38 \mathrm{~B}$, NO. 1, FEBRUARY 1956

$\mathrm{O}$ 
The fact that an appreciable proportion of the offspring of an affected patient (probably at least 30 per cent) is liable in due course to develop the disease is of considerable therapeutic importance. If all such children were kept under observation from birth it should be possible to identify those who are going to be affected at a very early stage of the development of the condition. This would enable active therapy to be begun early enough to prevent any deformity developing and perhaps to result in quite normal growth.

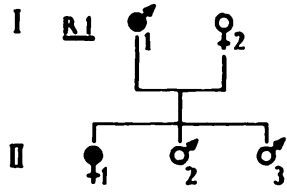

III

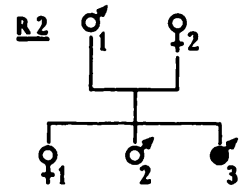

$\underline{\text { R2 }}$ $\underline{\text { R } 8}$

II

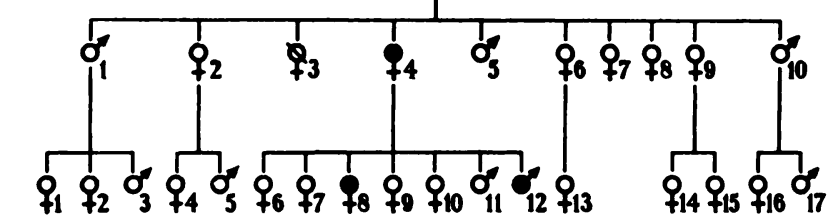

Fig. 4
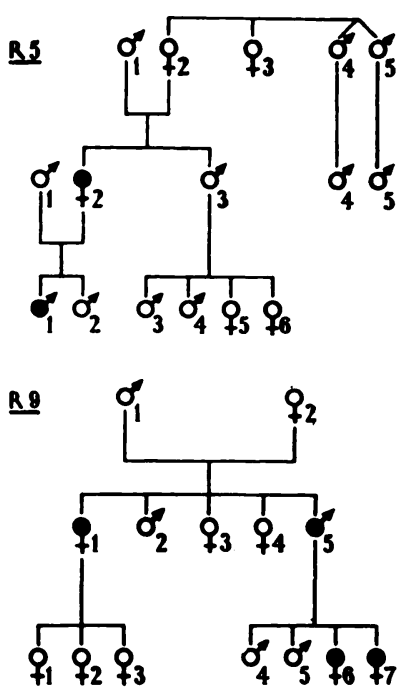

Representative family trees ( $R 1, R 2, R 5, R 8, R$ 9) of some of our cases of florid rickets presenting in infancy. In this and subsequent pedigrees affected members are shown in black; a line drawn obliquely through the circle means died in infancy.

If it is true that the clinical disorder is not manifest in a proportion of individuals carrying the abnormal gene, a number of problems of considerable physiological interest are raised. It might be that careful study would reveal slight deviations from the normal in such individuals and enable them to be recognised and further investigated with a view to discovering why no gross physiological disturbances have occurred. So far our preliminary attempts to identify such individuals on the basis of their heights and bodily proportions, or on the levels of their plasma inorganic phosphate, have not been successful. It seems possible that if such deviations do occur they will only be detected by rather more refined procedures. Studies of renal-tubular function with respect to phosphate where both parents are apparently normal would be of obvious interest.

\section{MILDER RICKETS PRESENTING IN CHILDHOOD WHICH CLOSELY MIMICS DIETARY DEFICIENCY OF VITAMIN D AND REQUIRES MODERATELY LARGE DOSES TO PRODUCE HEALING}

It is interesting that we have seen a very few examples of a syndrome which is almost identical with the one described above except that we suspect that the manifestations are rather milder and that the curative dose of vitamin $D$ is much less. Other authors, such as Pedersen and McCarroll (1951), in their excellent review, have also suggested that there are varying degrees of severity in resistant rickets. In this milder form it may be that the parents may have noticed nothing wrong with the child till four or five years of age, or even later. In some cases the rachitic deformities have been corrected by osteotomy and no further complaints have been made apart from lack of stature until adult life, when at the age of thirty or over signs and symptoms of osteomalacia appear. The biochemical findings are exactly the same in blood and urine as in the previous syndrome, except that we suspect that 
the plasma phosphorus may be a little less low and more variable. The main difference, however, is in the response to treatment, for good clinical and radiological cure can be obtained with 0.5-1.0 milligram a day of oral calciferol, whereas, as already mentioned, 5-10 milligrams are required for the more severe form of this disease.

We have only been able to study two families with patients of this sort. So far as our data go it appears that the condition runs true to type in the particular families, so that all the affected members in a family appear to require similar treatment. In one family a woman aged fifty-four, her son aged twenty-eight and the son's daughter aged five, all showed the condition. In the other a mother and her daughter were affected, whereas a son was normal. It is likely therefore that the condition is inherited in much the same way as the more severe type, and that the affected individuals are heterozygous for a rare abnormal gene. Whether the disease assumes a less severe form in these cases because a different gene is concerned, or whether it is the same gene and other factors lead to a modification of its expression, remains to be determined.

\section{SEVERE OSTEOMALACIA PRESENTING IN EARLY ADOLESCENCE OR ADULT LIFE AND VERY CLOSELY MIMICKING DEFICIENCY OF VITAMIN D}

This is an exceedingly rare syndrome with only a few other descriptions like it in the literature, as for instance the case described by McCance (1947). We have studied carefully four cases of this disease: two were girls, presenting in the late 'teens; and two were men, presenting in their twenties. In the case of the youngest member the first sign was that from the age of twelve years she ceased to grow. A waddling gait developed two years later. However, unambiguous osteomalacic aches and pains were not noted until she was sixteen. At the age of twenty she had gross radiological changes of osteomalacia with softening of bones and Looser zones. The other girl presented more acutely at the age of nineteen with aches and pains, muscular weakness and a waddling gait, and showed well calcified bones radiologically but with multiple Looser zones. The two men presented rather similarly but showed marked loss of height as possibly the first symptom. All four patients had straight limbs, and otherwise showed no stigmata of previous rickets.

It is rather characteristic of these cases that very marked muscular weakness is present, and indeed in one of our cases it was so gross that the patient lay immobile in bed unable to raise his head off his pillow and scarcely able to move his arms and legs. The first diagnosis made in his case was of progressive muscular atrophy, and we have heard of other similar cases which had been for some time confused with myopathies and neurological diseases. Apart from all this, however, the patients enjoy excellent general health. Biochemically they are very similar to the two previous types, already described, of refractory rickets with a plasma calcium usually between 9 and 10 milligrams per cent, phosphorus of 1-2 and a raised alkaline phosphatase. Like the other cases too, these patients do not get tetany.

There is a further curious finding which we are in the course of investigating and which was present in all four of our cases, namely a moderately lowered plasma bicarbonate level. This is a most important fact to consider in the diagnosis since this finding is usually taken to indicate the presence of an acidosis, and an acidosis with osteomalacia or rickets at once makes us think of other syndromes, such as are usually described under the names of renaltubular acidosis. The main basis of treatment of this latter is with alkalis rather than with large doses of vitamin D; so it would be unfortunate to confuse the two. The chief clinical difference is that in true renal-tubular acidosis there is usually other evidence of renal damage, such as slightly raised blood urea, inability to acidify the urine, proteinuria, nocturia, defective concentration and dilution of urine. All these are absent in the syndrome under discussion, where the only detectable renal defect is diminished renal-tubular reabsorption of phosphate. Another biochemical difference is that the twenty-four-hour urinary calcium excretion is lower than normal in our syndrome and higher than normal in renal-tubular acidosis.

VOl. 38 B, NO. 1, FEBRUARY 1956 
This is a very serious condition and three of the four patients were almost completely crippled by the time they were referred to us. The treatment is with very large doses of vitamin $\mathrm{D}$, starting with, say, 5 milligrams a day of calciferol and raising the dose as necessary, judging mainly by the plasma phosphorus levels, and with the same working rule mentioned above that the plasma phosphorus should be raised to over 2.5 milligrams/100 millilitres, the calcium not over 11.5 , and the urine calcium not more than 400 milligrams/24 hours. This latter stipulation is particularly difficult to uphold in this syndrome and the patients are therefore in considerable danger of renal stone formation. One of our patients had to receive 20 milligrams a day of calciferol for a long time, and we are continually faced with the problem that the curative dose for the rickets is often a dose which produces hypercalcaemia with its attendant complications. Indeed, one of our cases, treated and intoxicated already elsewhere, showed paradoxically enough signs of both ectopic calcification and of osteomalacia at the same time. Treatment of these patients has not been too satisfactory in the past but we are very hopeful that we are greatly improving it at the moment by using different forms of vitamin $\mathrm{D}$. This work is not ready for publication. It is interesting that the muscular weakness which plays so large a part in the clinical syndrome disappears on treatment with vitamin $D$. The plasma bicarbonate usually rises a little on the vitamin $\mathrm{D}$, sometimes to normal or low normal levels.

An interesting biochemical finding has been that all four of our patients had a high excretion of one aminoacid-glycine-in their urine. We allude to this matter again later in this paper.

In none of the families of these patients have we observed any other relatives to be affected nor was there any parental consanguinity. However, with such small experience of the disease we cannot exclude a hereditary factor and prefer in any case to mention it here among the proved hereditary diseases because of its very close clinical and biochemical relationship. It is of great interest that McCance's original patient (1947) has now apparently made a spontaneous recovery after having initially required large doses of vitamin D. We understand that she has now maintained herself well for some years without treatment, without symptoms and with normal plasma, calcium, phosphorus and phosphatase levels (McCance, private communication).

\section{OTHER ASSOCIATED FINDINGS IN RICKETS AND OSTEOMALACIA OF ABOVE TYPES}

While nearly all the cases we have seen of non-acidotic rickets or osteomalacia can be included in one or other of the above three categories, it is only too painfully obvious that the matter is indeed far more complicated than this and that it will only be a matter of time before we have to extend further the descriptions of distinct syndromes. As an indication of the way this may go we will now mention some further findings in some of these diseases.

Osteomalacia has now been described as a rare concomitant of neurofibromatosis (Hernberg and Edgren 1949, Dent 1952, Swann 1954; Saville, Nassim, Stevenson, Mulligan and Carey 1955). This association appears rather too frequent to be fortuitous and suggests some common causal relationship. The osteomalacia presents in adult life and closely resembles the severe adult presenting form described above. It is not correlated with any particular clinical form of neurofibromatosis. Neurofibromatosis is well known to be inherited. It is determined by a rare abnormal gene for which the patients are heterozygous. It is markedly variable in its manifestations. Whether or not the syndrome of neurofibromatosis with osteomalacia represents a rare variant determined by the same gene, or whether we are concerned with an entirely new situation, cannot be decided at the moment because of the paucity of family material, and because of our ignorance of the underlying biochemical disturbance which leads to neurofibromatosis. We are not aware of a case of neurofibromatosis associated with proven refractory rickets in childhood. 


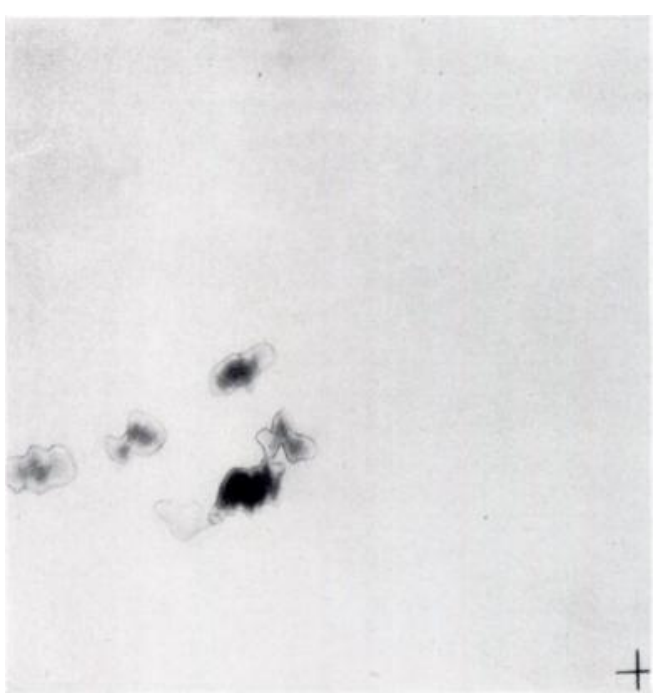

Fig. 5

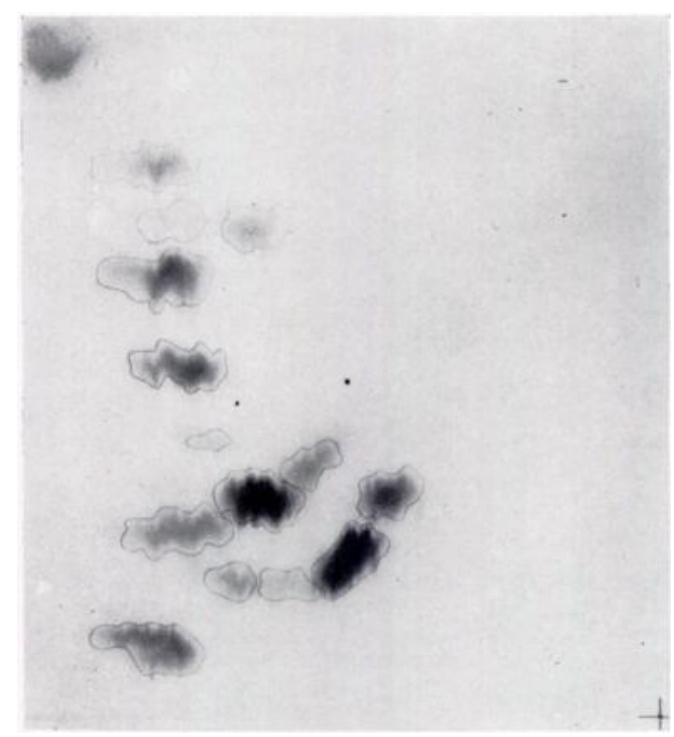

FIG. 7

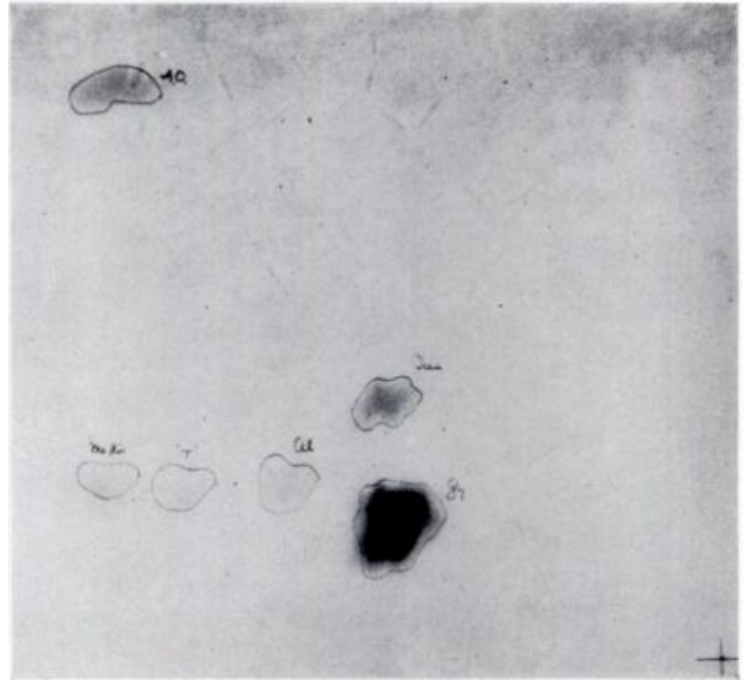

FIG. 6

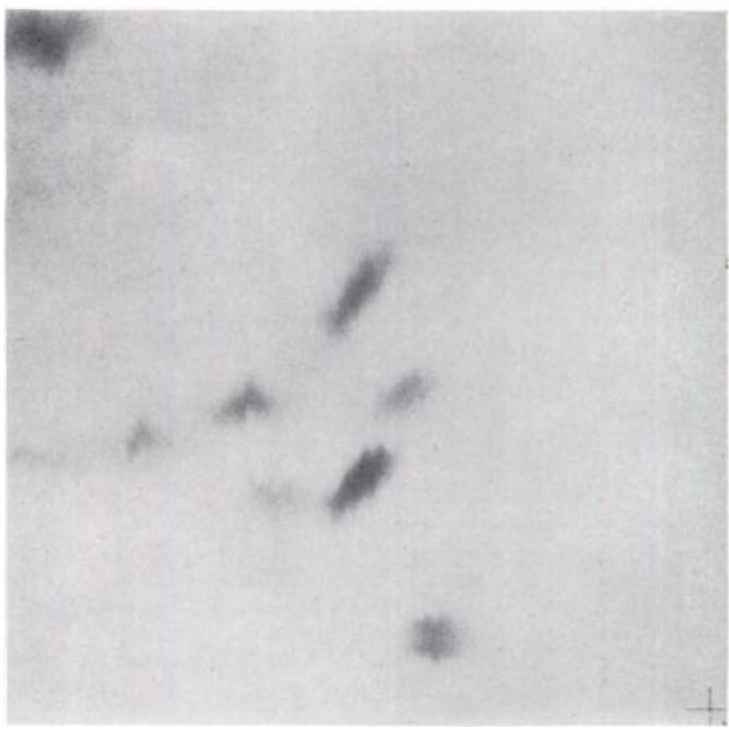

Fig. 8

Paper chromatograms of urine showing main aminoacids present. The measured amount of urine has been placed on the cross at the lower right-hand corner of the square of filter paper, and phenol and then collidine have been soaked across the paper in the usual way in the directions from right to left, and upwards, respectively (Dent 1948). The aminoacids are then revealed as purple spots on the paper, each one in its appointed place. They may be identified by reference to a published "Map of the spots" (Dent 1951). Figure 5-Normal urine. This specimen shows an aminoacid excretion at the upper limit of normal. On such a specimen the quite normal "glycine pattern "-so called because the strongest spot is due to glycine-can be easily seen and compared with the pathological urine patterns. Figure 6-Urine from a patient with severe osteomalacia presenting in early adolescence. This shows the "super-glycine pattern" mentioned in the text characterised by disproportionate excretion of one aminoacid only-namely glycine-which is seen as the largest spot on the paper and which is much stronger relative to the other spots than it is in Figure 5. Figure 7-Urine from a case of Lignac-Fanconi disease or cystinosis. The chromatogram shows a large number of strong spots widely distributed over the paper which indicate the generalised aminoaciduria characteristically found in these patients. This was the patient III 4, shown on family tree $F 3$ of Figure 15 . Other data from this patient are in Figures 10 to 12. Urines from the adult form of this disease show an identical aminoacid pattern on the chromatogram. Figure 8-Urine from a case of hypophosphatasia. The only conspicuous abnormality here is in the lowest spot shown on the chromatogram. This spot is due to phosphoethanolamine, a substance never found in normal urine by our methods. The remaining spots appear at the upper limit of normal strength owing to the fact that more urine than usual was taken for analysis on this chromatogram.

VOL. 38 B, NO. 1, FEBRUARY 1956 
Craniostenosis has now been several times described together with our first form above of florid rickets presenting in infancy (Imerslund 1951, Coleman and Foote 1954). It is of interest that Case 7 of Bickel, Smallwood, Smellie and Hickmans' (1952) series of Lignac-Fanconi syndromes also had craniostenosis. This child showed many features not typical at all of the Lignac-Fanconi syndrome, and indeed he resembled much more closely our first form of florid rickets. It is curious that such premature closure of sutures should ever, even if rarely, occur in a disease characterised by poor calcification and retarded bone age.

Albinism occurred in a case of florid rickets presenting in infancy described by Winberg. Bergstrand, Engfeldt and Zetterström (1954). The same authors described another case with a similar form of rickets, this time, however, associated with alopecia totalis. One of our own cases (unpublished) has also had this latter complication.

The remaining associated findings all concern renal-tubule function abnormalities. They are of special interest in providing evidence relating to theories of etiology, whether for instance primary tubule dysfunction is the cause of the disease, or whether it is due to a more generalised disorder of vitamin D metabolism. It seems that the phosphate reabsorption defect in the renal tubule can be equally well explained in either of these two ways. The association of these other tubule abnormalities does make it almost impossible at the moment to explain it on the basis of the third possible theory, namely that it is due to secondary hyperparathyroidism. This latter is probably the most popular theory at the moment for accounting for the phosphate defect, but in our opinion it does not explain the known facts.

Renal glycosuria is now a well established feature of some cases of non-acidotic rickets and osteomalacia (Lièvre, Bloch-Michel, Sassier and Solignac 1948; Dent 1952). Its theoretical interest led one of us to classify these cases under a different name from the others (Type II of Dent 1952). Unfortunately we have not yet had such a case under our own clinical control. All these cases, and indeed the other types of hereditary rickets and osteomalacia also, require accurate measurement of the renal tubule reabsorption maximum $\left(T_{m}\right)$ for glucose. Until this is done, both before and after treatment with vitamin D, we will remain in some doubt as to its significance.

Renal aminoaciduria has been known for some time to be a feature of the acidotic forms of rickets and osteomalacia to be described later. Less commonly it may occur without acidosis (Type III of Dent 1952) and in the only case followed up for some time we have noted that the aminoaciduria disappeared on treatment with vitamin D. A case of this syndrome has been well described by Kyle, Meroney and Freeman (1954). In these cases the aminoaciduria is generalised and concerns most of the commonly occurring aminoacids. Only recently, and at the instigation in the first instance of Dr P. Astrup, did we notice that a further abnormality could also occur which involved one aminoacid only-glycine. These patients excrete large quantities of glycine without any increase whatever in the other aminoacids. The pattern of aminoacid excretion as seen on paper chromatograms is rather characteristic (Fig. 6). It has been found in all four of our cases of severe late-presenting osteomalacia (above) but also in some few cases of the florid rickets presenting in infancy. We are unable to interpret these findings at the moment. Our theoretical interest in such aminoacidurias must now be reassessed in the light of the recent work of Jonxis (1955) on classical rickets. He has reported a renal aminoaciduria as occurring in vitamin D deficiency, which largely disappears on treatment with vitamin D. The pattern of aminoacid excretion in classical rickets is quite different from that which may be found in any of our hereditary forms of rickets and osteomalacia. We must take note, nevertheless, of the new action of vitamin $\mathrm{D}$ that has been revealed by this work.

THE SO-CALLED “ ORGANIC ACIDURIA " SYNDROME OF LOWE, TERREY AND MACLACHLAN

A most interesting disorder was described by Lowe et al. (1952). Its main features were “ organic aciduria," decreased renal ammonia production, congenital glaucoma, and mental 
retardation. However, of the three patients described two had rickets which was readily cured with large doses of vitamin D and alkalis, and all three had rarefaction of their bones. The syndrome was complex, for there were also behaviour abnormalities, aminoaciduria, proteinuria, intermittent glycosuria and a chronic acidosis. The urinary findings closely resembled those of the Fanconi syndrome, although clinically the two diseases are quite different.

We have been fortunate enough to diagnose a further example of this syndrome in a patient who was admitted to University College Hospital under Dr B. Schlesinger. This child was twelve years old and presented with a florid rickets with dwarfism and gross deformities and he also had most of the other signs described by Lowe et al. It is hoped that this case will be published fully later. We mention it here because of its exceptional interest in that an older brother of the child had obviously had the same syndrome but had unfortunately died some years ago during orthopaedic treatment (Fig. 9). There was no evidence in the case reports of Lowe et al. that the syndrome was hereditary.

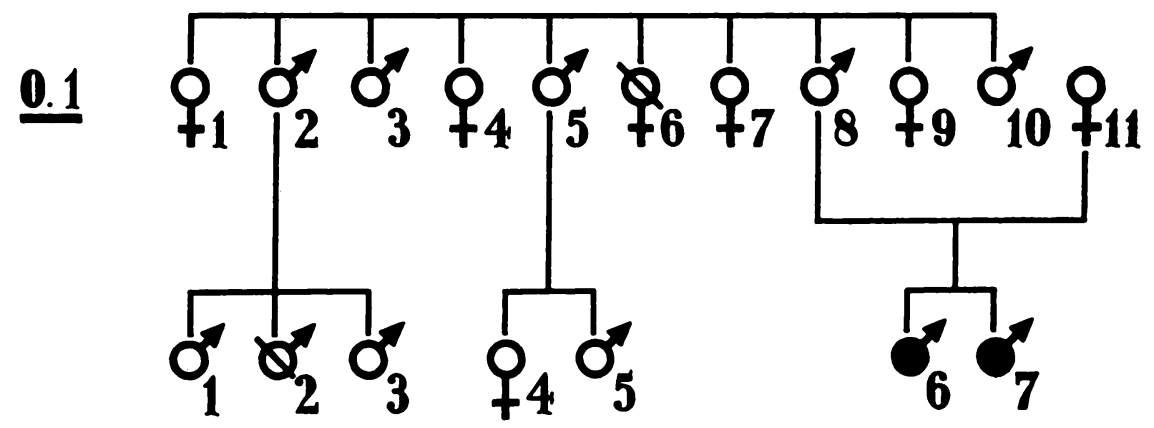

Fig. 9

Family tree (0.1) of a case of the so-called " organic-aciduria " syndrome of Lowe, Terrey and MacLachlan (1952).

We have not completed our biochemical studies, but so far as they go they are similar to those of Lowe et al., the only conspicuous difference being that we have not confirmed the excretion of increased amounts of organic acid as distinct from aminoacid.

\section{LIGNAC-FANCONI DISEASE OR CYSTINOSIS \\ (DE TONI-FANCONI SYNDROME, FANCONI SYNDROME, Etc.)}

The clinical picture of this most interesting disease has been dealt with rather thoroughly (Bickel, Smallwood, Smellie and Hickmans 1952) so it is not necessary to deal with this in any detail here. The children present usually at the age of about two years with failure to thrive, backward development and rickety deformities. The marked differences between this disease and those which have so far preceded it in this paper is that the children are iller and have many of the signs of chronic renal failure, namely feeding difficulties, thirst, lassitude and a great susceptibility to infections or to febrile reactions of unknown origin. They often get tetany. For this reason the patient is much more likely to be seen first by the paediatrician rather than, as in the other diseases reviewed here, by an orthopaedic surgeon. A preliminary examination would show a slightly raised blood urea with normal or low plasma calcium, phosphorus and bicarbonate levels. Phosphatase is usually raised. The urine is constantly dilute and contains from traces to large amounts of protein. It is clear that at first the vague diagnosis of " renal rickets" is likely to be applied to these cases together with the hopeless prognosis that this description usually implies. It should have been noted, however, that the plasma phosphorus level is lower than would be expected for this degree of renal failure, and further examination of the urine will show the presence of glucose and

vol. 38 B, NO. 1, fEBrUARY 1956 
of large quantities of aminoacids (Figs. 5 to 8). It is important, too, and usually easy, to examine the cornea with a small beam of light and hand lens for the presence of cystine crystals, which appear in the form of small gritty particles. Under slit lamp examination and with a magnification of thirty to fifty times, the individual crystals can be seen as tiny needles. This latter finding is pathognomic of the disease. The radiographs, if taken after one year of age, show florid rickets without any suggestion of secondary hyperparathyroidism. The disease represents one of the best examples of severe renal-tubule damage with only relatively small damage to the renal glomerulus. The disease is therefore characterised by excessive loss of substances from the body rather than by retention of excretory products and it is this that makes it easier to treat than other forms of renal failure, for the treatment merely comprises

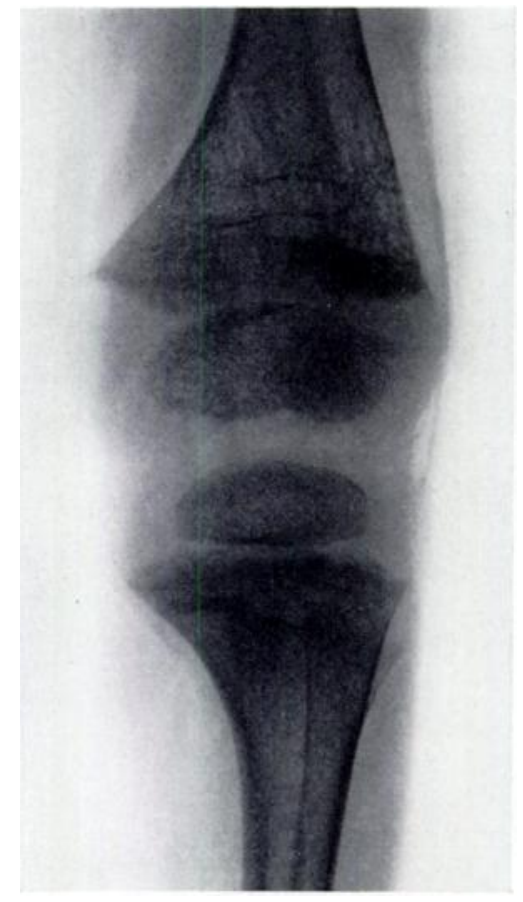

Fig. 10

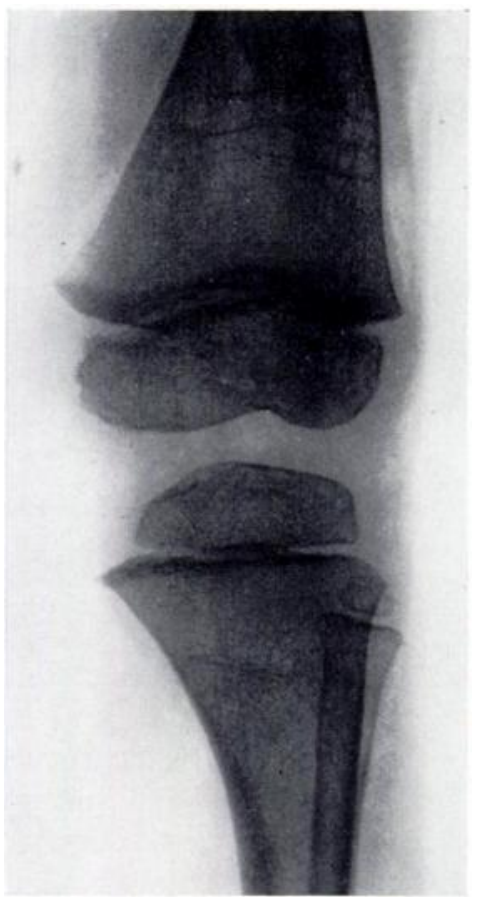

Fig. 11

Radiographs of knees of one of our patients with Lignac-Fanconi disease before and after seven months' treatment. The times correspond to the two arrows shown in Figure 12. It is seen that marked growth has occurred of normally trabeculated bone. The original coarsely trabeculated rachitic bone with its lines of arrested growth can be seen in Figure 11 farther along the shafts beyond the recently laid down normal bone. There is also a slight bulge there corresponding to the original splayed-out metaphyses. These radiographs are identical in appearance with those that may be obtained from cases of classical vitamin D deficiency rickets before and after treatment.

giving by mouth quantities of such substances as are being lost in the urine in sufficient amounts to cause a metabolic derangement, together with a sufficient dose of vitamin D to correct some of the other metabolic defects (Dent 1952, Bickel and Smellie 1952). Under this treatment the rickets can be cured (Figs. 10 and 11) and the child's symptoms almost completely alleviated. In the past all these children died young from severe infections or electrolyte crises. We do not yet have sufficient follow-up data to indicate what the long-term prognosis is but they can certainly be made very much better for many years. It appears at the moment that after three or four years growth slows down (Fig. 12) and renal-glomerular damage increases, so that unless improved forms of treatment are forthcoming they will probably die in uraemia in childhood. It is interesting that Bickel and Thursby-Pelham (1954) have shown 
that some at least of the signs of tubule damage are not present at birth. Although most of the evidence for tubule damage when it is found is of a biochemical nature, it is to be noted that Clay, Darmady and Hawkins (1953) have put this on a morphological basis by their microdissection studies of the nephrons from these cases. They have shown that there is, as might be expected from the biochemistry, a gross abnormality of the proximal tubule (Figs. 13 and 14). This is shorter than normal and is joined to the glomerulus by a narrow swan-like neck.

The genetics of the disease has already been discussed in a preliminary fashion by Bickel and Harris (1952). Subsequent work has supported their preliminary conclusions that the disease was due to an autosomal recessive gene. Typical family trees are shown in Figure 15.

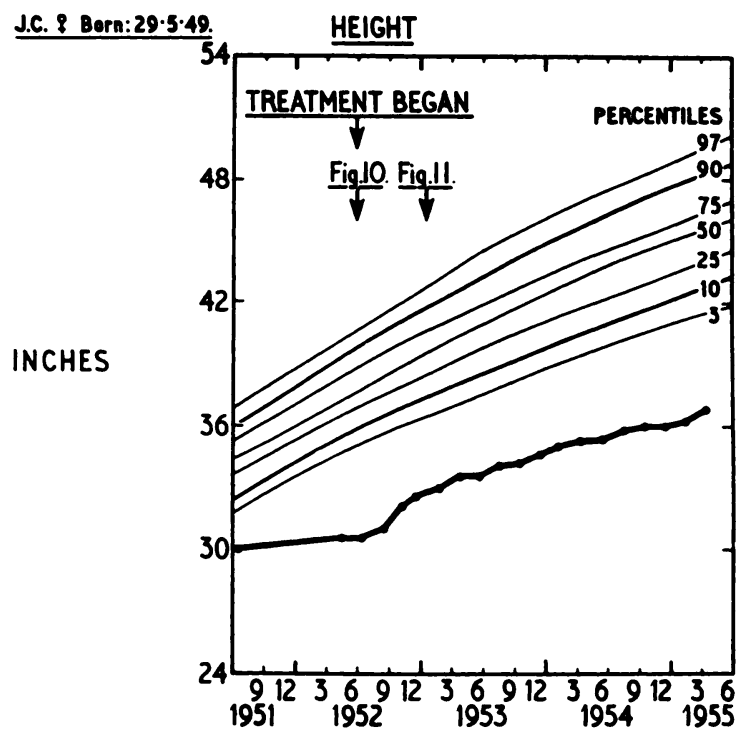

Fig. 12

Growth curve from a case of Lignac-Fanconi disease. It can be observed that she is very dwarfed as against the normal percentiles for her age and that she hardly grew at all when she was receiving no treatment during the nine months before being sent to us. When treatment began a spurt of growth occurred which is actually faster than normal for that age, as shown by the slope of the line being steeper than normal. After a year, however, growth began to slow down. This is our usual predicament.

Note the occurrence of the disease in only one sibship in each family and the first cousin parents in F 5 and F 7. The disease is remarkably homogenous, especially among affected members who are siblings. According to Bickel and Harris (1952) all of their fourteen cases of the disease had cystinosis - that is, there was microscopical evidence of cystine deposition in the body. In our view one occasionally sees cases, clinically and biochemically identical with theirs, in whom it is not possible to prove the presence of cystine storage. Post-mortem material from such a case is necessary for detailed chemical analysis as a negative microscopic finding is difficult to interpret. So far, post-mortem material has been only from cases in which clear cystinosis had been diagnosed in life. Analysis of the spleens of these patients shows that 3 per cent or so of the wet weight is pure cystine. This is up to a thousand times more than the normal quantity (Cusworth, Dent and Fowler, unpublished data).

VOL. 38 B, NO. 1, FEBRUARY 1956 


\section{MILD CHRONIC RICKETS AND OSTEOMALACIA WITH MANY SIGNS OF RENAL-TUBULE DYSFUNCTION}

Recently we have been able to recognise that there is a group of cases that are different from those with Lignac-Fanconi disease, although resembling it closely in many respects. In this group the rickets is usually much less likely to be a presenting sign. More often it is the symptoms of renal damage which are first complained of. There may be feeding difficulties, vomiting, "acidosis" dating from early life, and usually there is a very gross thirst and polyuria. The rickets, if it does present at all, is likely to do so later in childhood or adolescence than in the Lignac-Fanconi syndrome, but clearly some mild degree of rickets is present from an early age since dwarfism is a constant feature. We have studied carefully only four of these cases and have good records of a fifth from another hospital. In all cases but one the renal damage was not detected in childhood and the rickety deformities, if any, had been

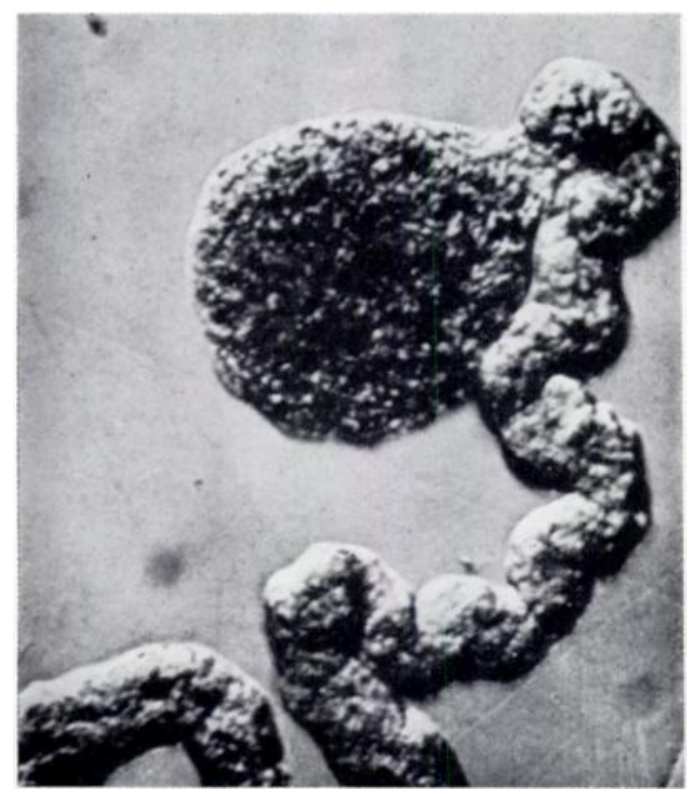

FiG. 13

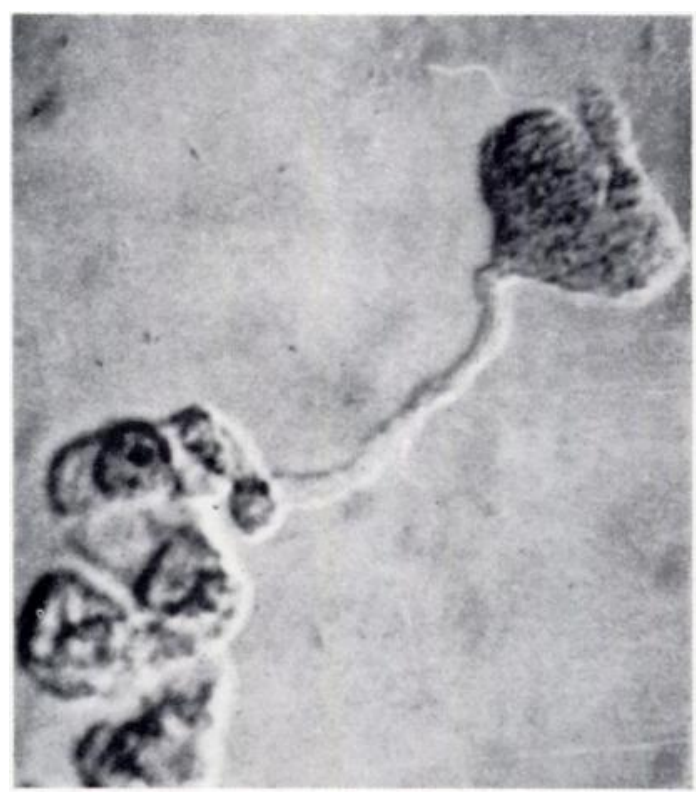

FIG. 14

Photomicrographs of dissected nephrons taken from Figures 2 and 5 of Clay, Darmady and Hawkins (1953). The glomerulus and the first part of the proximal tubule is shown in each case. A normal nephron $(\times 160)$ is shown in Figure 13; a nephron ( $\times 95$ ) from a case of Lignac-Fanconi disease (Case III 2, of family $F 7$ of Figure 15) is shown in Figure 14. Note that in this Figure the first part of the proximal tubule adjacent to the glomerulus is grossly abnormal.

corrected by osteotomy without further note of the disorders of renal function present. The two cases that have reached adult life have then presented at the age of thirty and forty years with the signs and symptoms of osteomalacia, but even then their shortness of stature indicates the long duration of some bone disease and careful history-taking has always elicited an almost life-long disease. Investigation shows biochemical findings identical with those in the Lignac-Fanconi disease except that these cases do not have cystinosis and that their urine calcium excretion is higher and not, as in the other syndrome, lower than normal. The treatment is based on the same general principles as in the other forms of renal-tubule disease: one replaces electrolytes lost in the urine, such as sodium bicarbonate, and gives sufficient vitamin D to correct the other abnormalities, especially the low plasma phosphorus level. It is of special interest that two patients have died with cirrhosis of the liver and a third patient we have under observation has a slightly enlarged hard liver with apparently normal function. We originally described cases such as this under the name "Fanconi syndrome" 
and wondered if the cirrhosis of the liver was due to the chronic loss of aminoacids in the urine (Stowers and Dent 1947). Our present view is that cirrhosis of the liver does not occur in the other syndromes mentioned here, many of which also have gross aminoaciduria. The cirrhosis is not, therefore, very likely to be due to the aminoaciduria, However, it may still be that the duration of the aminoaciduria is longer in this syndrome than in the others, and that therefore the aminoacid depletion is also greater.

As yet we have no evidence that the condition is hereditary but more cases must be studied before this can be considered further. The disease is certainly present soon after birth and does not progress much subsequently. Hence, if the renal damage is acquired rather than hereditary then it must be a very curious form of renal damage. In one of our cases, a short-statured boy who presented at the age of thirteen with mild rickets and knock-knee, we have some evidence for the presence of a urethral valve with some obstruction to urinary flow. It is unfortunate that no nephron dissection studies have yet been reported from cases such as this.

\section{" FANCONI SYNDROME" PRESENTING FIRST IN MIDDLE AGE}

Of all the problems of nomenclature in the various forms of rickets it is in this syndrome that things are most confused. However, we and others have used the term "Fanconi syndrome" for an adult syndrome, which is quite extraordinarily similar to that occurring in children and more correctly given this name. As there is no better name for it we prefer to continue calling it thus for the time being.

The disease presents around the age of forty as a typical osteomalacia of the more acute type (Dent and Hodson 1954) in which the bones become tender, show Looser zones on radiography, but otherwise appear of fairly normal structure and density. The patient may have noted some loss of height and after some time a moderate degree of muscular weakness also develops. He does not get tetany, and renal symptoms, while always present, may be inconspicuous. Biochemically the plasma levels are typical of those of an acidotic osteomalacia with normal or slightly lowered calcium, low phosphorus, low bicarbonate and raised phosphatase. The plasma potassium is usually a little lowered, as occurs in other forms of renal-tubular acidosis, and one of our patients (the same one as first described in detail by Milne, Stanbury and Thomson 1952) also had quite typical attacks of low potassium paralysis. The urine, however, is the most interesting feature. It contains large quantities of aminoacids and glucose just as in the children's form of this syndrome, and there is a defect of acidification whereby a load of ammonium chloride by mouth does not produce an acid urine, at least until the plasma bicarbonate level has been very greatly lowered. There is also protein in the urine and other tubule function defects such as inability to concentrate or dilute adequately. These adult cases of the Fanconi syndrome do not have cystinosis as detected microscopically or by chemical analysis of organs. Another marked biochemical difference between the syndrome and the Lignac-Fanconi disease is in the urine calcium output. This tends to be lower than normal in the children with Lignac-Fanconi disease but is usually greatly raised in the adult syndrome. Despite these differences it must be pointed out that the apparently highly characteristic morphological defect of the proximal tubule of the nephron is the same in both child and adult forms of the syndrome (Clay, Darmady and Hawkins 1953).

This disease is difficult to diagnose clinically, although it is exceedingly easy to diagnose biochemically once the possibility has been considered. Clinically the patient presents with symptoms that are not at all specific. He may be feeling some backache or complain of rheumatic pains in his feet or hips. As his bones show no gross rarefaction or deformities radiographically, and as the Looser zones may not appear early in the disease and even when present may be very difficult to find, it is easy to see how patients may be undiagnosed until they are seriously ill. By our genetic studies we have been able to detect cases of this syndrome before the occurrence of clinical signs of disease. These patients have later presented with

VOL. 38 B, NO. 1, FEBRUARY 1956 
quite severe bone pains which showed nothing on radiographic examination but which completely disappeared on giving the specific treatment. Such cases are quite undiagnosable by ordinary means. We refer to this matter again in the discussion.

Treatment has been very satisfactory. It comprises giving doses of sodium or potassium bicarbonate and of vitamin $\mathrm{D}$ sufficient to correct the metabolic abnormalities, using the
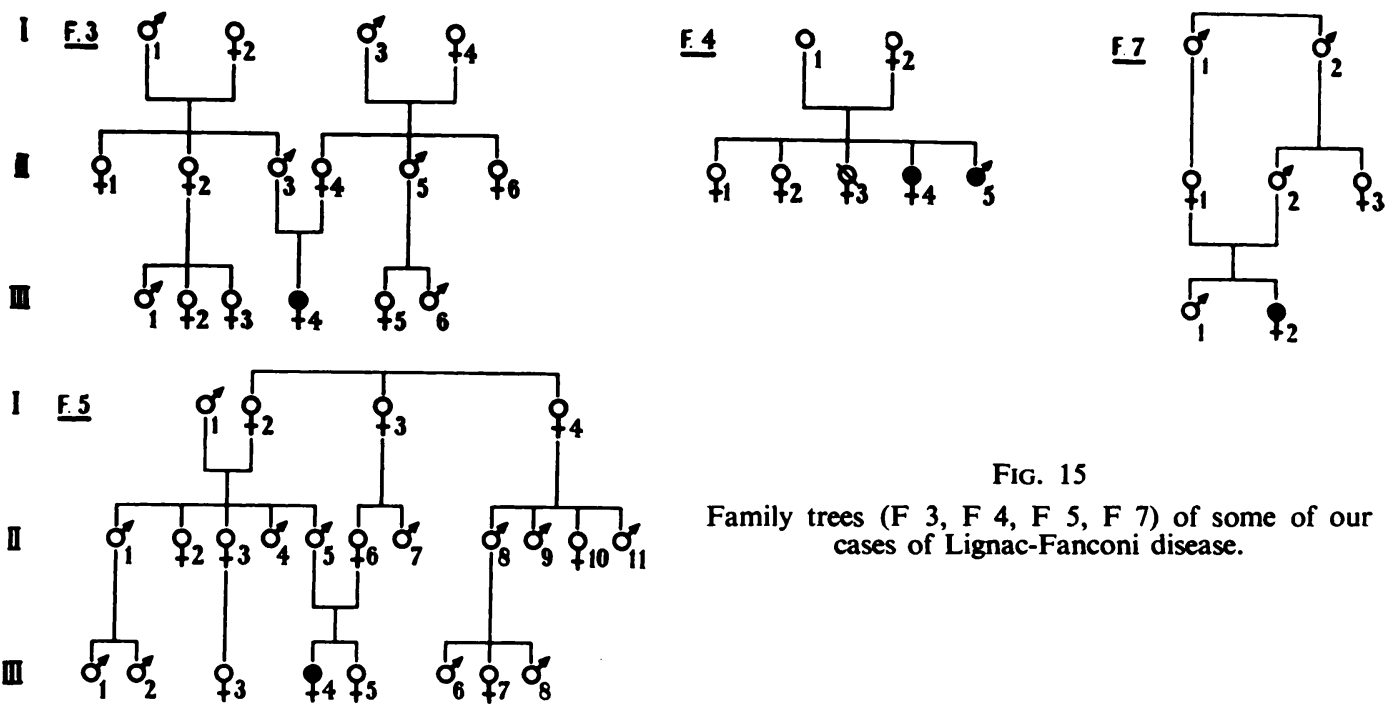

Fig. 15

Family trees (F 3, F 4, F 5, F 7) of some of our cases of Lignac-Fanconi disease.

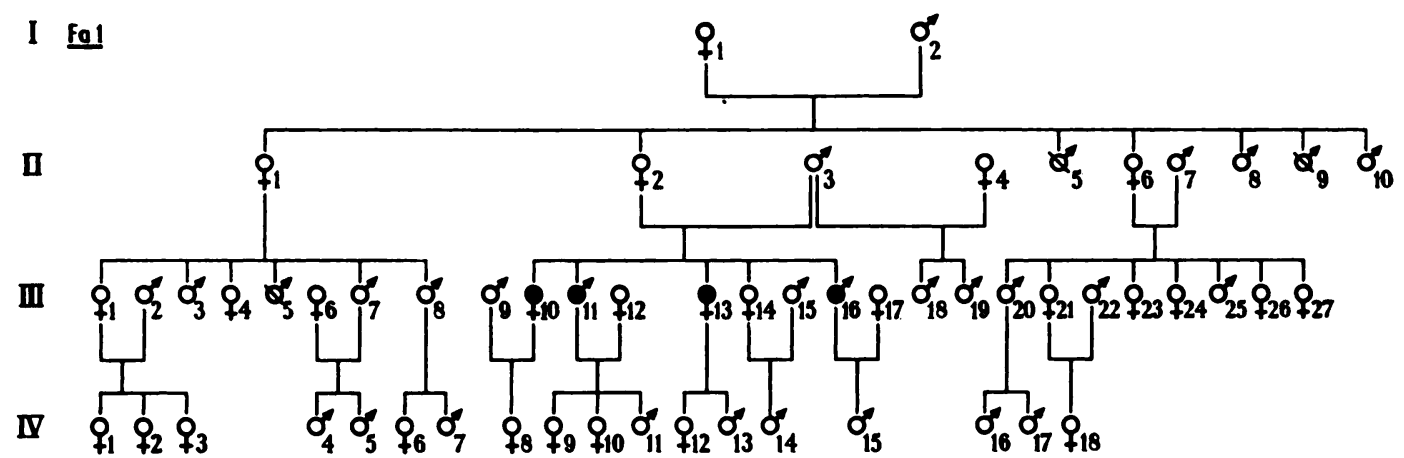<smiles>COC(C=O)(CO)C(C=O)(CO)CC=O</smiles>

FIG. 16

Family trees (Fa 1, Fa 2) of some of our cases of " Fanconi syndrome" presenting first in middle age. Fa 1 has already been reported (Dent and Harris 1951).

same criteria as in the treatment of other forms of acidotic osteomalacia. The high urine calcium which these patients have has to be rather carefully watched in case it rises further with the vitamin D. It is a curious fact, however, that these patients to our knowledge have never formed stones nor developed nephrocalcinosis, in spite of the fact that this is usual with patients who have other forms of renal-tubular acidosis and in whom the same features predisposing to stone formation are present, namely neutral urine with a high calcium content. 
We wonder whether the aminoaciduria in this syndrome exerts a protective action against stone formation. This is possible on theoretical grounds.

Two of the families in which this condition has occurred are shown in Figure 16. The simplest hypothesis is that the condition is inherited as a Mendelian recessive character. Its relation to the childhood form of the syndrome remains a difficult problem. In so far as the two conditions run true to type in individual families it seems that different abnormal genes must be involved. It would be of interest to know whether these genes were at different chromosomal loci, or were alleles. If they were found to be alleles this would probably mean that the series of underlying biochemical disturbances leading to the clinical syndrome would be qualitatively very similar though different in degree.

\section{HYPOPHOSPHATASIA}

This most interesting hereditary biochemical disorder of bone was first described as such by Rathbun (1948) in an infant in whom there was defective calcification of bone with softening of the skull and deformities of the limbs superficially suggesting rickets. Biochemically the blood showed raised calcium, phosphorus and non-protein nitrogen levels, with low, almost undetectable alkaline phosphatase levels. The infant died and the bones were found to show osteoid hyperplasia with disorganised calcification as in severe rickets. However, the suggestion was made that in this condition the osteoblasts were unable to produce alkaline phosphatase and that this was the primary defect and the cause of the bone disease. Since then a few more cases have been described (Sobel, Clark, Fox and Robinow 1953, Schlesinger, Luder and Bodian 1955), and the original findings of Rathbun confirmed and extended. It seems likely that the condition is hereditary, because relatives of the affected patient often show chronically low alkaline phosphatase levels while being apparently clinically normal. The genetic studies of this condition are not, however, yet suitable for publication. The affected children's general health is comparatively good and it is beginning to appear that they make a spontaneous recovery after a few years. Many cases of this syndrome may have been already described under other names-for instance Case 2 described by Anspach and Clifton (1939), in which the suggestion was made that the child had hyperparathyroidism on account of its raised plasma calcium level. Cases which may well have been of hypophosphatasia have also been described as having unusual forms of renal rickets (Chown 1936, Schneider and Corcoran 1950). We wonder too whether some of the cases described as atypical chondrodystrophies may not have been cases of hypophosphatasia. It is rather fun to try to rediagnose cases that have been fully enough described in the past. Of especial interest to us was the adult patient with fragile bones and a very low alkaline phosphatase described by Macey (1940). We think it is quite likely that this case was an adult survivor of the children's disease because he had had the "rickets" in childhood and had got much better in later childhood. In the children's disease it appears that the diagnosis can be reliably made by paper chromatographic analysis of the urine for aminoacids (Cusworth and Dent 1955). This does not reveal an aminoaciduria but a gross abnormality of rather unusual kind, namely a very large excretion of phosphoethanolamine (McCance, Morrison and Dent 1955, Fraser, Yendt and Christie 1955), a substance which is not detectable in normal urine (Fig. 8). Dr Henneman (Boston) has kindly sent us recently a urine specimen from an adult with fragile bones who resembles very closely clinically the patient described by Macey. We were intrigued to note that his urine showed exactly the same abnormality as the children with hypophosphatasia. It appears that it may be possible to make a little more sense soon out of an obscure corner in orthopaedics - namely the problem of fragile bones and of some obscure bone dystrophies.

OTHER RARE CAUSES OF OSTEOMALACIA

Osteomalacia may occasionally arise as a consequence of a true metabolic disorder occurring in a much more complex clinical syndrome. In such situations the reason for the infrequent association of osteomalacia with the more obvious primary disorder present may

VOL. 38 B, NO. 1, FEBRUARY 1956 
at first sight appear rather obscure. It is possible that something of this sort happens in neurofibromatosis, as has been mentioned earlier. Probably a clearer example is the case of Wilson's disease.

This neurological disorder is well known to be hereditary, and it is now clear that the affected patients are homozygous for a rare abnormal " recessive" gene (Bearn 1953). The clinical manifestations are variable in onset, rarely beginning in childhood, more commonly in adolescence, and occasionally delayed still further. It is now thought possible that the underlying biochemical disturbance is a failure to synthesise in normal amounts the coppercontaining plasma protein ceruloplasmin (Scheinberg and Gitlin 1952). This failure for some reason leads to an excessive absorption of copper from the gut (Cartwright et al. 1954) and to its consequent slow deposition in the tissues throughout life. Copper is deposited most extensively in the brain and liver, and the characteristic lesions that develop can be attributed to the toxic effects of the large amounts of copper which slowly accumulate in these sites. The variable onset of the clinical condition is presumably due to variable rates of copper absorption from the gut and possibly to variations in the copper content of the diet. The condition illustrates very clearly one aspect of the nature-nurture problem. The individual has an inborn incapacity to cope adequately with one specific aspect of his environment, namely the copper content of the diet.

Among the diverse features of this disease there has recently been described renal-tubule dysfunction. This can probably be attributed like the other lesions to the toxic effects of excessive copper deposition. Usually aminoacid reabsorption is most markedly disturbed (Cooper, Eckhardt, Faloon and Davidson 1950), but dysfunction in glucose and uric acid reabsorption has also been encountered in a proportion of cases. It is probable that phosphate reabsorption is also occasionally involved because some cases of Wilson's disease have been described (Warnock 1952, Cooper et al. 1950) with radiological and biochemical signs of osteomalacia. The tubular damage is clearly very variable both in onset and extent, and this is no doubt because it is a rather remote reflection of the fundamental disorder of copper metabolism, attributable to the presence of a particular abnormal gene in double dose. The occasional occurrence of osteomalacia in Wilson's disease can thus be understood as a rather distant consequence of an underlying genetical abnormality.

Similar renal-tubule damage and osteomalacia has also occurred in what is usually accepted as an acquired disease. This is the most interesting case of multiple myelomatosis described by Engle and Wallis (1954), in whom, after some years, typical renal-tubule abnormalities developed-renal glycosuria, aminoaciduria and acidosis-with subsequent development of the typical syndrome of adult osteomalacia with multiple Looser zones.

Hence it appears clear that the same bone disease can be caused by the same renal-tubule disorder, even when of widely different etiology.

\section{DISCUSSION}

We have described the various forms of rickets and osteomalacia which we have been able to study clinically and genetically and in most of which we consider hereditary factors to be mainly responsible for the disease. The great majority of the cases we have seen belong to one or other of the forms we have described. Perhaps we should summarise here those features of more immediate clinical value which may have arisen from this study.

In the first place, we hope that we have made clear that there is often excellent treatment for hereditary diseases. There is still some misunderstanding of this matter: for instance, even certain British authors have stated in a paper describing a case of the Fanconi syndrome: "The condition being a congenital and often hereditary defect of the renal tubules, treatment is unfortunately of little avail." It is our view that the hereditary or acquired nature of a disease has no bearing whatever as to whether or not we can, or at least can hope to, treat it adequately. With this more optimistic approach to the study of hereditary diseases, we can 
now make a further obvious point that, in adisease in which progressive bone or other damage occurs, the sooner the diagnosis is made the better. Here the hereditary diseases enjoy a great advantage over acquired ones, since it is only in them that the onset of a disease can sometimes be to some extent predicted. This point is illustrated in our case history (described briefly by Dent and Harris 1951) and subsequent follow-up (unpublished) of a family ( $\mathrm{Fa} 1 \mathrm{of} \mathrm{Fig.} \mathrm{16)}$ in which a case of the adult Fanconi syndrome had been diagnosed. The patient (III 13) was completely crippled when we first saw her and gave a seven-year history of increasing pain, weakness and general misery. It took over six months' medical treatment before she could be returned to her normal activity. Our family study showed that three of her four siblings had the biochemical features of her disease while having no complaints whatever. These three have been kept under observation and have all subsequently developed clinical signs of the disease, which we have now been able to treat very effectively within a very short time of its appearance. In the youngest member of this sibship the clinical signs only developed recently, that is, five years after we had first detected his biochemical abnormality on the original family survey. It is clear, therefore, that whenever one of the diseases described in this paper is diagnosed in a patient, it is our responsibility to examine as many as possible of the remaining members of the family, however symptom-free they may appear at the time. It is here that a knowledge of the mode of inheritance is of great advantage.

In the case of recessive disorders one in four of the brothers and sisters may be expected on the average to develop the condition. The risks so far as the children of a patient are concerned are on the other hand very low, unless the patient happens to have married a first cousin. In the case of dominant or partially dominant conditions there is a risk approaching one in two, according to the rate of manifestation, that the brothers and sisters of an affected individual will develop the disorder, and a similar risk that the children of such patients will also be affected. The development of appropriate screening tests to detect such predisposed individuals is one of the most important tasks of research in this field. In the Fanconi syndromes routine examination of the urinary aminoacids has proved the most useful to date. In the other syndromes the investigation of young children with respect to the phosphate, calcium and phosphatase levels in the plasma, and appropriate radiography of the bones, would seem at present to be the most useful way of identifying the potentially affected individuals at the earliest possible time. We cannot stress too much the fact that true hereditary diseases need not be congenital. They may be manifested at any time from foetal life until well on in later life.

With regard to the help which one can get from genetic studies in making a more accurate diagnosis of patients with rickets or osteomalacia, there are several points to be made. The most important is, of course, that the clinical diagnosis must be one which is consistent with the known facts of its inheritance. The occurrence of an entirely different mode of inheritance of a condition seemingly identical clinically with a form previously recognised would imply some difference in causal relationships. One would be suspicious, for instance, if the diagnosis of Fanconi syndrome had been made in both a parent and child of the same family in the absence of consanguineous marriage. The next point concerns the rather remarkable homogeneity of each disease when it does recur more than once in a family. This not only helps in diagnosis but it also means that the results of extensive investigation and treatment of one of the patients can be used directly to benefit the others. This is particularly noticeable with regard to such points as the dose of vitamin D that is necessary to cure the disease. A further way of saying the same thing is that if in a family with a diagnosed case of bone disease another patient with bone disease presents himself, these diseases are almost certain to be the same. We had an interesting example of this from a mistake brought to our notice on one occasion. This concerned a woman who had radiological signs of pathological fractures and abnormal biochemical findings. She was diagnosed as having a parathyroid tumour and was twice, without success, explored surgically, once in the neck and once in the chest, for the tumour.

VOL. 38 B, NO. 1, FEBRUARY 1956 
It was not until after this that it was noticed that her daughter had been under treatment for some years at a children's hospital for one of the forms of metabolic rickets. It then at once became clear that the mother really had the same disease. This was confirmed and the mother is now doing well on the same medical treatment as her daughter.

Many further problems remain in studies of this kind which we should like to mention in the hope that others will be better able to deal with them. One of these concerns the problem of orthopaedic correction of deformed bones in patients whom we know we can treat adequately by medical means. It is most important that attempts should be made to correct deformities of the vertebrae, for instance, when the disease is first diagnosed, so that when the bones have been strengthened the patient ends up in more normal shape. It may be feasible too to straighten bent malacic long bones and deformed pelves before treatment hardens them.

Another unsolved problem concerns a more purely genetic matter, that of detecting heterozygotes in the diseases in which we know the mode of inheritance to be recessive. By a comparison of the disordered metabolism of heterozygotes and homozygotes we may be able to determine the effects of an abnormal gene in single and double dose. Furthermore the development of methods for detecting such individuals would enable us to predict more accurately the chances of further children being born with the disease. We are often asked about the future children of apparently normal relatives of patients, for instance, with the Fanconi syndrome. Their chance of being themselves heterozygous for the abnormal gene is very high, but of course they will not bear abnormal children unless they should happen to marry another person who is also heterozygous for that gene. Clearly they are likely to do this if they marry into their own family or into any other family which has an affected member, and we can advise them of the probable risk should they wish to do this. Should they marry into an apparently normal family, however, we have no way of telling what may happen, although the risk fortunately is then always rather small. It is quite likely that very sensitive tests for the abnormalities present in the homozygous patients could be developed which would be capable of detecting the heterozygotes but, except possibly in hypophosphatasia, this most desirable objective has not yet been achieved in any of the recessive diseases discussed here.

\section{SUMMARY}

1. We have described here various forms of rickets and osteomalacia that we have studied ourselves and have come to recognise as comprising definite syndromes. We have included only diseases in which hereditary factors have been proved or might be suspected to play a part.

2. There are more of these syndromes than previously defined.

3. All these hereditary diseases can be treated, usually very satisfactorily, using the same general principles and with only very few simple medicines such as vitamin $D$ and sodium bicarbonate. Careful control and long follow-up, however, may be required to achieve best results and to avoid accidents.

4. A study of the genetics of the diseases is a help in diagnosis and treatment. Broadly speaking the group of diseases which mimic vitamin D deficiency more or less closely tend to be inherited in dominant fashion. The groups with more severe degree of renal-tubule abnormality are inherited as recessives.

5. When more than one member of a family is affected it has been found that in each family each syndrome runs true to type.

We sincerely thank the clinicians, too numerous to mention by name, who, by referring cases to us, have enabled these investigations to be carried out; and who have also helped us in very many other ways. We wish to thank also Miss Barbara Warland for her assistance in the family case work. 
REFERENCES

Anderson, J., Dent, C. E., Harper, C., and Philpot, G. R. (1954): Effect of Cortisone on Calcium Metabolism in Sarcoidosis with Hypercalcaemia: Possibly Antagonistic Actions of Cortisone and Vitamin D. Lancet, ii, 720. ANSPACH, W. E., and Clifton, W. M. (1939): Hyperparathyroidism in Children: Report of Two Cases. American Journal of Diseases of Children, 58, 540.

BEARN, A. G. (1953): Genetic and Biochemical Aspects of Wilson's Disease. American Journal of Medicine, 15, 442.

Bickel, H., and Harris, H. (1952): The Genetics of Lignac-Fanconi Disease. Acta Paediatrica, 42, Supplement 90, 22.

Bickel, H., Smallwood, W. C., Smellie, J. M., and Hickmans, E. M. (1952): Clinical Description, Factual Analysis, Prognosis and Treatment of Lignac-Fanconi Disease. Acta Paediatrica, 42, Supplenent 90, 27. Bickel, H., and Smellie, J. M. (1952): Cystine Storage Disease with Amino-Aciduria. Lancet, i, 1,093.

Bickel, H., and Thursby-Pelham, D. C. (1954): Hyperamino-Aciduria in Lignac-Fanconi Disease, in Galactosaemia and in an Obscure Syndrome. Archives of Disease in Childhood, 29, 224.

Bonham Carter, R. E., Dent, C. E., Fowler, D. I., and Harper, C. M. (1955): Calcium Metabolism in Idiopathic Hypercalcaemia of Infancy with Failure to Thrive. Archives of Disease in Childhood, $30,399$.

Cartwright, G. E., Hodges, R. E., Gubler, C. J., Mahoney, J. P., Daum, K., Wintrobe, M. M., and Bean, W. B. (1954): Studies on Copper Metabolism. XIII. Hepatolenticular Degeneration. Journal of Clinical Investigation, 33, 1,487.

Chown, B. (1936): Renal Rickets and Dwarfism: A Pituitary Disease. British Journal of Surgery, 23, 552.

Clay, R. D., Darmady, E. M., and Hawkins, M. (1953): The Nature of the Renal Lesion in the Fanconi Syndrome. Journal of Pathology and Bacteriology, 65, 551.

Coleman, E. N., and Foote, J. B. (1954): Craniostenosis with Familial Vitamin-D-Resistant Rickets:- British Medical Journal, i, 561.

Cooper, A. M., Eckhardt, R. D., Faloon, W. W., and Davidson, C. S. (1950): Investigation of the Aminoaciduria in Wilson's Disease (Hepatolenticular Degeneration): Demonstration of a Defect in Renal Function. Journal of Clinical Investigation, 29, 265.

Cusworth, D. C., and Dent, C. E. (1956): Symposium on Bone Structure and Metabolism. Ciba Foundation. In the press.

DENT, C. E. (1948): A Study of the Behaviour of Some Sixty Amino-Acids and other Ninhydrin-Reacting Substances on Phenol- "Collidine" Filter-Paper Chromatograms, with Notes as to the Occurrence of Some of them in Biological Fluids. Biochemical Journal, 43, 169.

Dent, C. E. (1951): Paper Chromatography and Medicine. In Recent Advances in Clinical Pathology. General Editor S. C. Dyke. Second edition, p. 238. London: J. \& A. Churchill Ltd.

DENT, C. E. (1952): Rickets and Osteomalacia from Renal Tubule Defects. Journal of Bone and Joint Surgery, 34-B, 266.

Dent, C. E., and Harris, H. (1951): Genetics of "Cystinuria." Annals of Eugenics, 16, 60.

Dent, C. E., and Hodson, C. J. (1954): Radiological Changes Associated with Certain Metabolic Bone Diseases. British Journal of Radiology, N.S. 27, 605.

ENGLe, R. L., Jun., and Wallis, L. A. (1954): Studies of an Unusual Patient with Plasmacytosis. Journal of Clinical Investigation, 33, 931.

FaIrbank, Sir T. (1951): An Atlas of General Affections of the Skeleton. Edinburgh: E. \& S. Livingstone Ltd. Fancon, G. (1951): Úber chronische Störungen des Calcium- und Phosphatstoff-wechsels im Kindesalter. Schweizerische Medizinische Wochenschrift, 81, 908.

Fraser, D., Yendt, E. R., and Christie, F. H. E. (1955): Metabolic Abnormalities in Hypophosphatasia. Lancet, i, 286.

Henneman, P. H., Carroll, E. L., and Dempsey, E. F. (1954): The Mechanism Responsible for Hypercalcuria in Sarcoid. Journal of Clinical Investigation, 33, 941.

HeRnBerg, C. A., and EDGREN, W. (1949): Looser-Milkman's Syndrome with Neurofibromatosis Recklinghausen and General Decalcification of the Skeleton. Acta Medica Scandinavica, 136, 26.

IMERSLuND, O. (1951): Craniostenosis and Vitamin D Resistant Rickets. Acta Paediatrica, 40, 449.

JACKSON, W. P. U., and Linder, G. C. (1953): Innate Functional Defects of the Renal Tubules, with Particular Reference to the Fanconi Syndrome. Quarterly Journal of Medicine, N.S. 22, 133.

JonXIS, J. H. P. (1955): Amino-Aciduria and Rickets. Helvetica Paediatrica Acta, 10, 245.

Kyle, L. H., Meroney, W. H., and Freeman, M. E. (1954): Study of the Mechanism of Bone Disease in Hypophosphatemic Glycosuric Osteomalacia. Journal of Clinical Endocrinology, 14, 365.

LEHMANN, W. (1936): Die Bedeutung der Erbveranlagung bei der Entstehung der Rachitis. Zeitschrift für Kinderheilkunde, 57, 603.

Lièvre, J. A., Bloch-Michel, H., Sassier, R., and Solignac, H. (1948): Le diabète rénal phospho-glucidique [ostéoporose avec diabète rénal chez l'adulte]. Bulletins et Mémoires de la Société Médicale des Hôpitaux de Paris, 64, 769.

Vol. 38 B, NO. 1, FEBRUARY 1956 
Lightwood, R. (1952): Idiopathic Hypercalcaemia with Failure to Thrive. Proceedings of the Royal Society of Medicine (Section of Paediatrics), 45, 401.

Lowe, C. U., Terrey, M., and Maclachlan, E. A. (1952): Organic-Aciduria, Decreased Renal Ammonia Production, Hydrophthalmos, and Mental Retardation: a Clinical Entity. American Journal of Diseases of Children, 83, 164.

MCCANCE, R. A. (1947): Osteomalacia with Looser's Nodes (Milkman's Syndrome) due to a Raised Resistance to Vitamin D Acquired about the Age of 15 Years. Quarterly Journal of Medicine, N.S. 16, 33.

McCance, R. A., Morrison, A. B., and Dent, C. E. (1955): The Excretion of Phosphoethanolamine and Hypophosphatasia. Lancet, i, 131.

MACKAY, H., and MAY, Q. I. (1945): Rickets Resistant to Vitamin D: Healing with Very Heavy Dosage of Vitamin D, Fluctuations in Vitamin D Requirement, Development of Hypercalcaemia. Proceedings of the Royal Society of Medicine (Section for the Study of Disease in Children), 38, 565.

MACEY, H. B. (1940): Multiple Pseudofractures: Report of a Case. Proceedings of the Staff Meetings of the Mayo Clinic, 15, 789.

Milne, M. D., Stanbury, S. W., and Thomson, A. E. (1952): Observations on the Fanconi Syndrome and Renal Hyperchloraemic Acidosis in the Adult. Quarterly Journal of Medicine, N.S. 21, 61.

Pedersen, H. E., and McCarroll, H. R. (1951): Vitamin-Resistant Rickets. Journal of Bone and Joint Surgery, 33-A, 203.

Pfaundler, M. (1911): Úber Wesen und Behandlung der Diathesen im Kindesalter. Verhandlungen des Deutschen Kongresses für Innere Medizin, 28, 36.

Rathbun, J. C. (1948): “Hypophosphatasia": A New Developmental Anomaly. American Journal of Diseases of Children, 75, 822.

Robertson, B. R., HARRIS, R. C., and MCCune, D. J. (1942): Refractory Rickets: Mechanism of Therapeutic Action of Calciferol. American Journal of Diseases of Children, 64, 948.

Saville, P. D., Nassim, J. R., Stevenson, F. H., Mulligan, L., and Carey, M. (1955): Osteomalacia in von Recklinghausen's Neurofibromatosis: Metabolic Study of a Case. British Medical Journal, i, 1,311.

ScheinberG, I. H., and Girlin, D. (1952): Deficiency of Ceruloplasmin in Patients with Hepatolenticular Degeneration (Wilson's Disease). Science, 116, 484.

SCHlesinger, B., Luder, J., and Bodian, M. (1955): Rickets with Alkaline Phosphatase Deficiency: an Osteoblastic Dysplasia. Archives of Disease in Childhood, 30, 265.

Schneider, R. W., and Corcoran, A. C. (1950): Familial Nephrogenic Osteopathy due to Excessive Tubular Reabsorption of Inorganic Phosphate: a New Syndrome and a Novel Mode of Relief. Journal of Laboratory and Clinical Medicine, 36, 985.

Schreiner, G. E., Smith, L. H., Jun., and Kyle, L. H. (1953): Renal Hyperchloremic Acidosis: Familial Occurrence of Nephrocalcinosis with Hyperchloremia and Low Serum Bicarbonate. American Journal of Medicine, 15, 122.

SiegerT, F. (1903): Beiträge zur Lehre von der Rachitis. Jahrbuch für Kinderheilkunde, N.F. 58, 929.

Sobel, E. H., Clark, L. C., Jun., Fox, R. P., and Robinow, M. (1953): Rickets, Deficiency of " Alkaline" Phosphatase Activity and Premature Loss of Teeth in Childhood. Pediatrics, 11, 309.

Stowers, J. M., and Dent, C. E. (1947): Studies on the Mechanism of the Fanconi Syndrome. Quarterly Journal of Medicine, N.S. 16, 275.

SwanN, G. F. (1954): Pathogenesis of Bone Lesions in Neurofibromatosis. British Journal of Radiology, N.S. 27, 623.

ThATCHER, L. (1936): Hypervitaminosis D. Lancet, i, 20.

Warnock, C. G. (1952): Hepatolenticular Degeneration (Wilson's Disease). Ulster Medical Journal, $21,155$. Winberg, J., Bergstrand, C. G., Engfeldt, B., and Zetterström, R. (1954): Primary Vitamın D Refractory Rickets. I. Report of Two Cases Treated with High Doses of Vitamin D. Acta Paediatrica, 43, 347.

ZIESCH, H. (1925): Statistich-genealogische Untersuchungen über die Ursachen der Rachitis insbesondere ihre Erblichkeit. Archiv für Rassen- und Gesellschafts Biologie, 17, 61. 